Article

\title{
Performance Behavior of Participatory Water Institutions in Eastern India: A Study through Structural Equation Modelling
}

\author{
Nicky Johnson ${ }^{1} \mathbb{D}$, Vasant P. Gandhi ${ }^{1, *}$ and Dinesh Jain ${ }^{2}$ \\ 1 Indian Institute of Management Ahmedabad, Ahmedabad 380015, India; nickyj@iima.ac.in \\ 2 Entrepreneurship Development Institute of India, Ahmedabad 382428, India; dineshjain@iima.ac.in \\ * Correspondence: gandhi@iima.ac.in
}

Received: 16 December 2019; Accepted: 6 February 2020; Published: 11 February 2020

check for updates

\begin{abstract}
The paper examines the nature and performance of participatory water institutions in eastern India using structural equation modelling. There is a crisis in the management of water in India, and this is often not about having too little water but about managing it poorly. It is now being widely recognized that engineering structures and solutions are not enough, and having effective water institutions is critical. These are urgently needed in eastern India for helping lift the region out of low incomes and poverty. However, creating good institutions is complex, and in this context, the fundamentals of new institutional economics, and management governance theory have suggested the importance of a number of key factors including five institutional features and eight rationalities. Based on this, a study was conducted in eastern India, sampling from the states of Assam and Bihar, covering 510 farm households across 51 water institutions. In order to understand and map the relationship and pathways across these key factors, a structural equation model is hypothesized. In the model, the five institutional features are considered determinants of the eight rationalities, and the rationalities are considered determinants of four performance goals. The performance on the goals determines the overall performance/success of the institution. Besides this, the institutional features and rationalities can also directly influence performance on the goals and the overall performance. The model is tested with data from the survey and different pathways that are robust are identified. The results can provide useful insights into the interlinkages and pathways of institutional behavior and can help policy and institution design for delivering more robust performance. The results show that one of the most important factors determining overall performance/success is technical rationality, and this deserves great attention. It includes technical expertise, sound location and quality of structures and equipment, and good maintenance. However, success is also strongly linked to performance on production/income goals, equity, and environment goals. These are, in turn, strongly related to achievement of economic, social, technical, and organizational rationalities, which call for attention to economic aspects such as crop choice and marketing, besides social aspects such as inclusion of women and poorer social groups, and organizational aspects such as member involvement and regular meetings. Further, the institutional features of clear objectives, good interactions, adaptive, correct scale, and compliance are important for achievement of almost all rationalities through various pathways, and should be strongly focused on in all the institutions.
\end{abstract}

Keywords: water; institutions; participatory irrigation management; structural equation modelling; India

\section{Introduction}

The paper examines the nature and performance behavior of participatory water institutions in eastern India using structural equation modelling. The physical development of irrigation has 
made considerable progress in India, but substantial inefficiencies remain in the management and distribution of the water due to institutional weaknesses. Engineering solutions alone have proved inadequate since the difficulties lie mainly in poor institutional development and design [1-4]. These result in poor water use efficiency, inequity, conflicts, reduced crop productivity, environmental cost, and substantial under-utilization of the potential created. In some instances, however, better institutional initiatives and development can be seen, indicating learning and experience towards better institutional performance.

Eastern India, and particularly the eastern Indo-Gangetic plains, have relatively abundant water through the perennial Himalayan rivers that if effectively managed could support strong agriculture and economic growth, which could overcome the low incomes and high poverty incidence that exist in the region. Partly due to weak state capacity, the central government has played a larger role in eastern India, resulting in institutions that over-focus on top-down accountability rather than desired outcomes for the local population. A World Bank evaluation [5] identifies these institutional arrangements as a major weakness and highlights the importance of reforming them to bring in active participation of the stakeholders for better outcomes. The World Bank emphasizes on reshaping and transforming the institutional setup to create better institutional arrangements as critical for overcoming the vicious cycle of poor development in which the region is caught.

Even though water management and institutions have been identified as important concerns, and some of their features have been explored in the literature, no studies have examined the institutional arrangements in water through theoretical foundations of new institutional economics or management governance theory. A recent study has found the relevance of such foundations and has identified a set of characteristics including eight rationalities and five institutional features to be useful in explaining institutional performance [6]. However, the study does not examine how these characteristics interact with each other and what the relevant pathways across them are to determine performance on different goals and the overall success of the institution. This paper uses a structural equation modelling approach to examine this, bringing together the different characteristics identified by new institutional economics and management governance theories, and the various possibilities of interaction and pathways through them, to identify the critical interactions and pathways to institutional performance.

Section 2 discusses the origins of new institutional economics and the derived concepts that are used in this paper. It also discusses the concepts derived from management governance theory that are used to explain the performance behavior of water institutions. Section 3 discusses the nature of the survey data and the sample profile. Sections 4-6 discuss briefly the profile of the findings on the institutional features, the rationalities, and performance, respectively. Section 7 gives the conceptual framework for structural equation modelling (SEM) and some hypotheses. Section 8 states the research methods and describes the variables used. Section 9 covers the results and their discussion, and Section 10 provides the conclusions, as well as limitations and future research ideas.

\section{New Institutional Economics and Governance}

Institutional economics is believed to have originated during the 1920s and 1930s through the investigations of Ely and Commons [7-9]. The foundations were useful in explaining voluntary exchange and utility in the interactions of individuals [10]. Institutions were seen as collective actions for the control, release, and expansion of the activities of individuals. However, in this approach, institutions remained largely outside the domain of neoclassical economics, which saw tremendous growth and acceptance in the subsequent years. It was new institutional economics that brought institutions into the fold of neoclassical economics. New institutional economics justifies the existence of institutions through the concepts of transaction costs and property rights [11,12]. It is observed that the costs of organized economic activities include not just transformation costs but also transaction costs [13]. Institutions lower the transaction costs, and this is proposed as a principal reason explaining the existence of institutions. When transaction costs are high and ignored, performance generally 
suffers, so the challenge is to design institutions that lower transaction costs and create incentives favoring cooperative solutions [11].

Using new institutional economics and the related empirical literature [14-16], Pagan $[17,18]$ has identified the following features that sound water management institutions should have:

1. Clear objectives: If the institution has clear objectives that are accepted by all, this reduces conflicts as well as transaction costs.

2. Good interactions: If the interactions in the institution and among its different stakeholders are good, it helps lower transaction costs and promote cooperative solutions

3. Adaptiveness: Adaptiveness (not rigidity) in the institution improves inclusion and sustainability, lowering transaction costs.

4. Appropriate scale: Having the right scale in size, scope, and decision domains lowers transaction costs and improve effectiveness.

5. Compliance: Rules are critical to the institution and compliance to the rules is essential for lowering transaction costs.

Apart from these, based on management theory of organizational design [3,19-21] and applications in the context of water institutions [22], the following eight rationalities that need to be addressed by effective institutions have been identified:

1. Technical Rationality: Addresses the most efficient conversion of inputs to outputs.

2. Environmental Rationality: Addresses care and conservation of natural resources and the environment.

3. Economic Rationality: Addresses costs, benefits, and profits, which depend on prices, demand, markets, and infrastructure.

4. Social Rationality: Addresses social groups, their inclusion/involvement and equitable distribution of benefits.

5. Political Rationality: Addresses the need for representation of different leaders/powers and interest groups, for the perception of fairness and justice.

6. Organizational Rationality: Addresses good organization and coordination of activities, including managerial and leadership skills and knowledge.

7. Financial Rationality: Addresses discipline and care in the handling of money/financial resources.

8. Government Rationality: Addresses the appropriate laws, rules, and schemes of the government and effective government support.

Further details of the concepts, the context, and the ordered probit analysis supporting the relevance of the concepts are given in an accompanying paper [6]. The performance of the water institutions in the context of developing country settings such as India can be gauged on at least four goals (dimensions) of benefits/impact, including production/income, equity, environment, finance, as well as overall perceived performance/success [23].

\section{Survey Data and Sample Profile}

This study uses a conceptual framework developed on the basis of new institutional economics and management governance theory. Six in-depth case studies of water user associations in the eastern India states of Assam and Bihar were conducted. Based on the case studies and the conceptual framework, a detailed farmer-institutional survey instrument was designed. The households for the farmer-institutional survey were selected randomly from among the sample framework of the beneficiaries of the selected water user associations (WUAs), with an effort to cover various farm household sizes. The farmer-institutional survey (conducted by the authors) covered 510 households through face-to-face interviews: 252 in Assam and 258 in Bihar across 51 WUA village level committees (VLCs) (see Table 1). Standard Likert scales of 5 to 1 (strongly agree to strongly disagree) were used on specially designed specific questions. 
Table 1. Survey sample coverage.

\begin{tabular}{cc}
\hline State & Sample Size \\
\hline Assam & 252 \\
Bihar & 258 \\
\hline Total & 510 \\
\hline Total No. of Water User Associations & 51 \\
\hline
\end{tabular}

The sample profile of respondents indicates that the large majority of sample farmers covered were very small-where the marginal and small categories had land holdings of less than two hectares. This is typical of the area covered in India. The average land holding owned by sample farmers is only 1.22 hectares, showing very small farm sizes. Though the sample farmers had about $90 \%$ of their land irrigated, a majority of farmers reported facing water scarcity for agriculture, indicating the need for organization of irrigation. Despite the investment in irrigation and participatory irrigation management, about 60\% indicated that there was no improvement in water availability, though about $40 \%$ reported improvement.

With respect to the formation and running of the WUAs, about $60 \%$ disagreed that they were formed and managed by the government, and nearly $70 \%$ agreed that the WUAs were managed by the farmers. The responses about inclusion and representation indicate that even many disadvantaged groups, such as small/marginal farmers, lower caste/social groups, and tail-reach farmers, are included and represented on executive committees. Representation was also indicated for the landless/tenant farmers as well as those of minority religions. This indicates good pluralistic inclusion at the village level WUAs. Representation of the disadvantaged groups was also indicated at substantial percentages at the central level committee (CLC) level. This indicates that the WUAs are quite inclusive.

\section{Assessment on Institutional Features}

Relevant questions were designed and asked to assess the achievement/standing on different desirable institutional features that were derived from new institutional economics, as discussed above. About three to five questions were asked on each institutional feature to assess the status of those features using a Likert scale of 5 to 1: strongly agree to strongly disagree. The results indicate substantial variation in these features across the WUAs [6]. On clear objectives, $64.1 \%$ agreed (strongly agreed plus agree) that they have clarity of objectives and purpose, but only $46.9 \%$ agreed that WUA makes plans and actions, which indicates a lack of planning and action toward the achievement of the objectives. On good interaction, $60.8 \%$ agreed that there is good interaction between the WUA and the members/villagers, and $52.0 \%$ agreed regarding wide representation in the executive committees. However, only $44.1 \%$ agreed that there are regular and frequent meetings, which indicates a lack of an adequate number of meetings. On adaptiveness, only $44.5 \%$ agreed that there is adaptiveness to the needs and conditions by the WUA. Very few agreed (47.5\%) regarding any provision of process/review for adapting the rules and plans. This indicates inadequate adaptiveness in WUAs. On scale and size, the majority indicate that this is appropriate (65.1\%), and a majority also agreed $(58.6 \%)$ that the distribution of powers and responsibilities is satisfactory. Regarding compliance, many indicate that the rules of water distribution are not frequently broken (52.5\%), but only $30.8 \%$ agreed that penalties and fines are imposed for breaking WUA rules. Similarly, only $42.5 \%$ agreed that members recognize the authority of WUA to impose penalties. Overall, this indicates a lack of imposition of penalties and fines, and low recognition of the WUA as an authority.

\section{Assessment on Rationalities}

Relevant questions were also designed and asked to the sample farmers to assess the status under WUAs on the different rationalities mentioned above. About five to seven questions were asked on each rationality to assess the status of each institutional feature using a Likert scale of 5 to 
1: strongly agree to strongly disagree. The results indicate substantial variation in the achievement on different rationalities across the WUAs with poor achievement indicated by the farmers on many aspects [6]. On technical rationality, 83.9\% agreed (strongly agree plus agree) that the location and placement of structures is sound, but only $29.4 \%$ agreed that the structure and equipment are adequate. When it comes to maintenance and repair of the structures, only $39.4 \%$ agreed it is regular, indicating inadequacy in structures and equipment and poor maintenance. On environmental rationality, 52.5\% agreed that environmental problems are well addressed, and more than $60 \%$ agreed that there are no water logging issues due to irrigation activities. However, only $40.6 \%$ agreed that flooding and flood damage are promptly repaired. On economic rationality, $76.3 \%$ agreed that there is good economic value of irrigation water (even when water in the region is considered abundant). However, only $34.1 \%$ agreed that there is adequate infrastructure and marketing/processing arrangements to achieve good prices. On social rationality, over $80 \%$ agreed that participation and involvement of the various social groups is good. On youth involvement, only $41.8 \%$ agreed that there is active involvement. On political rationality, $76.7 \%$ agreed that there is adequate representation of experienced people in WUA, and wide inclusion and political support, and 57.5\% agreed that WUA is able to ensure fairness and justice. On organizational rationality, more than $60 \%$ agreed that the leadership is knowledgeable and competent, but only $45.3 \%$ agreed that the meetings are held regularly. On financial rationality, $62.2 \%$ agreed that there are good arrangements and control of funds, but only $41.8 \%$ agreed that funds received by WUA is adequate and financially sound. On government rationality, only $35.3 \%$ agreed that the government acts/laws are well formulated for WUAs. In terms of receiving funds from the government, only $11.2 \%$ agreed that WUA received funds on time. Only 23.9\% agreed that government officials are well trained and adequate to support WUAs. This indicates some deficiencies in government support.

\section{Assessment of the Performance of the Water User Associations}

The impacts of the WUAs on different goals including production/income, equity, environment, and finance were assessed through sets of relevant questions using a 5-point Likert scale (5: strongly agree to 1: strongly disagree). Composites of the responses on relevant questions were used to represent performance on each of the goals (dimensions). Further, the overall performance of WUAs was assessed through responses on a 5-point Likert scale (5: excellent to 1: very poor). Results on overall performance show that about $40 \%$ rated the performance as good and only $6 \%$ rated it as excellent. On the other hand, about $29 \%$ rated the performance as somewhat poor and $12 \%$ considered it very poor. Overall responses were also sought for the performance on different aspects including water availability, economic benefits, equity, environmental impact, and financial management. The findings showed that there was considerable variation. Good to excellent performance was reported by $31 \%$ for economic benefits, $35 \%$ for equity, $40 \%$ for environment, but only by $22 \%$ for finance. A composite of these overall performance indicators was used to represent overall success.

\section{Conceptual Framework for Structural Equation Modelling (SEM)}

The above mentioned institutional features and rationalities were combined into a conceptual framework that was then examined in this analysis, see Figure 1. In the structural equation model, the five institutional features were considered determinants for the achievement of each of the eight rationalities. Next, the eight rationalities were considered determinants of the outcomes on each of the four performance goals. Finally, the performance on the four goals determined the overall performance/success of the institution. Besides this, the institutional features and the rationalities can also directly influence the performance on the goals as well as overall performance. Based on this, four hypotheses were proposed with reference to participatory water institutions.

1. The institutional features would have a positive influence on the achievement of different rationalities. 
2. The achievement on various rationalities would have a positive relationship with performance on different goals (dimensions): production/economic, equity, environmental, and finance, and with overall success.

3. The performance on different goals (dimensions) of production/economic, equity, environmental, and finance would have a positive association with overall success.

4. Various institutional features would also have a positive association with performance on different goals (dimensions) and with overall success.

Figure 1 below illustrates the conceptual framework and shows the relationships between factors affecting the overall performance.

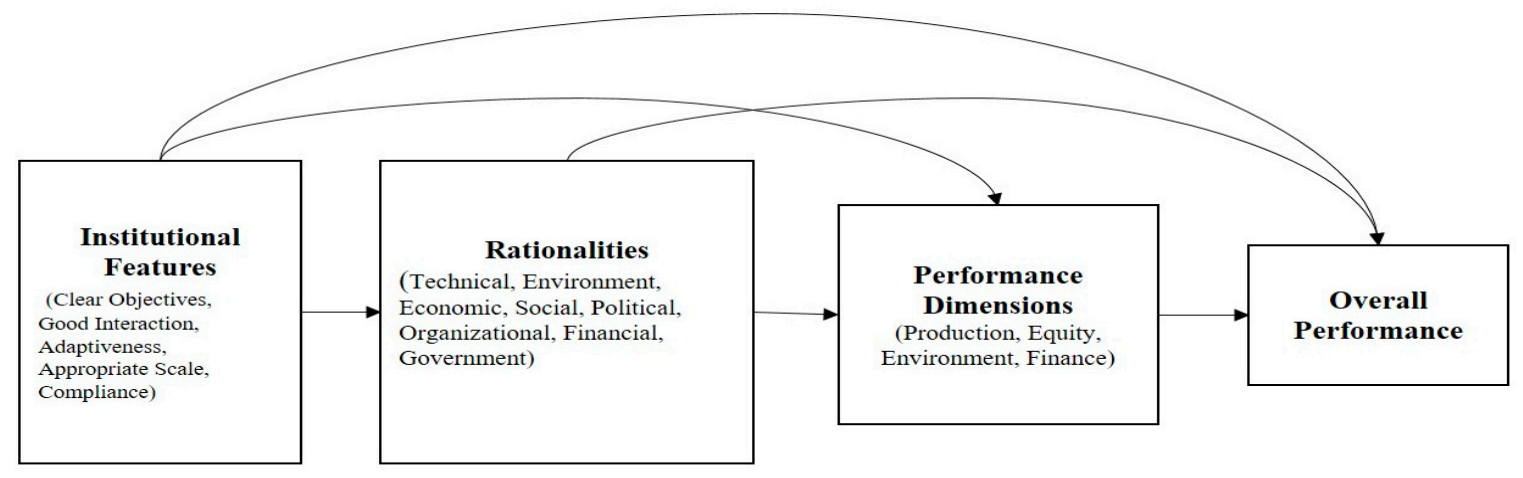

Figure 1. The conceptual framework.

\section{Research Methods}

\subsection{Modelling Strategy/Methodology}

This research framework involves institutional features and rationalities. In the model, individual relationship is estimated using institutional feature and the rationality variables. The latent constructs are created from various elements of the conceptual framework. These latent constructs have items commonly known as manifest variables. The items are responses to individual questions asked to respondents. For example, on Clear Objectives, questions such as "The WUA has clear objectives and purpose" were asked, and the respondents responded on a 5-point Likert scale, where 5 stands for "Strongly Agree" and 1 stands for "Strongly Disagree".

SEM is widely used in the fields of statistics, economics, management, and social sciences [24-27]. SEM (also called simultaneous equation modelling) is often considered a combination of factor analysis and multi-equation multivariate regression analysis [28]. It can be used as a confirmatory technique or for explanatory purposes [29]. SEM helps to find the relationships between the constructs through pathways [28]. The model may be complex and have too many variables, which makes estimation difficult, but the SEM technique helps find meaningful relationships with statistical efficiency [30].

\subsection{Structural Equation Model Estimation}

Initially, a test for multivariate normality was conducted and as a result 11 observations were removed. These observations had unusually high Mahalanobis distance values, which were high and significantly different from the other values. After removing these observations, the sample size was reduced to 499 . The model comprises 32 variables, of which 19 are observed variables and 13 are unobserved variables, see Table 2. If based on multiple questions the observed variables are their composites, then a state dummy is also included. To run the SEM model, the standard software package AMOS (Analysis of Moment Structures) was used, Arbuckle [31]. 
Table 2. List of variables used in the model.

\begin{tabular}{cc}
\hline Variable Code & Variable Name \\
\hline Overall Performance & \\
\hline OverallSucc & Overall Success/Performance \\
\hline Performance Dimensions & \\
\hline prodincImperform & \\
equityImperform & Impact on Production/Incomes \\
envImperform & Impact on Equity \\
finImperform & Impact on Environment \\
\hline Rationalities & Impact on Finance \\
\hline TechR & \\
EnvR & Technical Rationality \\
EcoR & Environmental Rationality \\
SocR & Economic Rationality \\
PolR & Social Rationality \\
OrgR & Political Rationality \\
FinR & Organizational Rationality \\
GovR & Financial Rationality \\
\hline Institutional Features & Government Rationality \\
\hline Clrob & \\
GooInt & Clear Objectives/Clarity of Purpose \\
Adap & Good Interactions \\
ScSz & Adaptiveness \\
Compl & Scale/Size \\
& Compliance \\
\hline
\end{tabular}

\subsection{Structural Equation Modelling Map}

Constructs were developed based on the conceptual framework presented in Figure 1, and the model was then estimated empirically. To confirm the model with minimum loss of information and good statistical accuracy, estimation was done using a recursive SEM. The pathways, estimates, and statistics are shown in the Figure 2. The rectangles represent the observed variables, and the circles represent the unique measurement errors. One-headed arrows represent the relationships between the variables, and two-headed arrows represent the covariance between the variables.

The values on the single-headed arrows are the standardized coefficients, and the values above the rectangle boxes show the squared multiple correlations. 


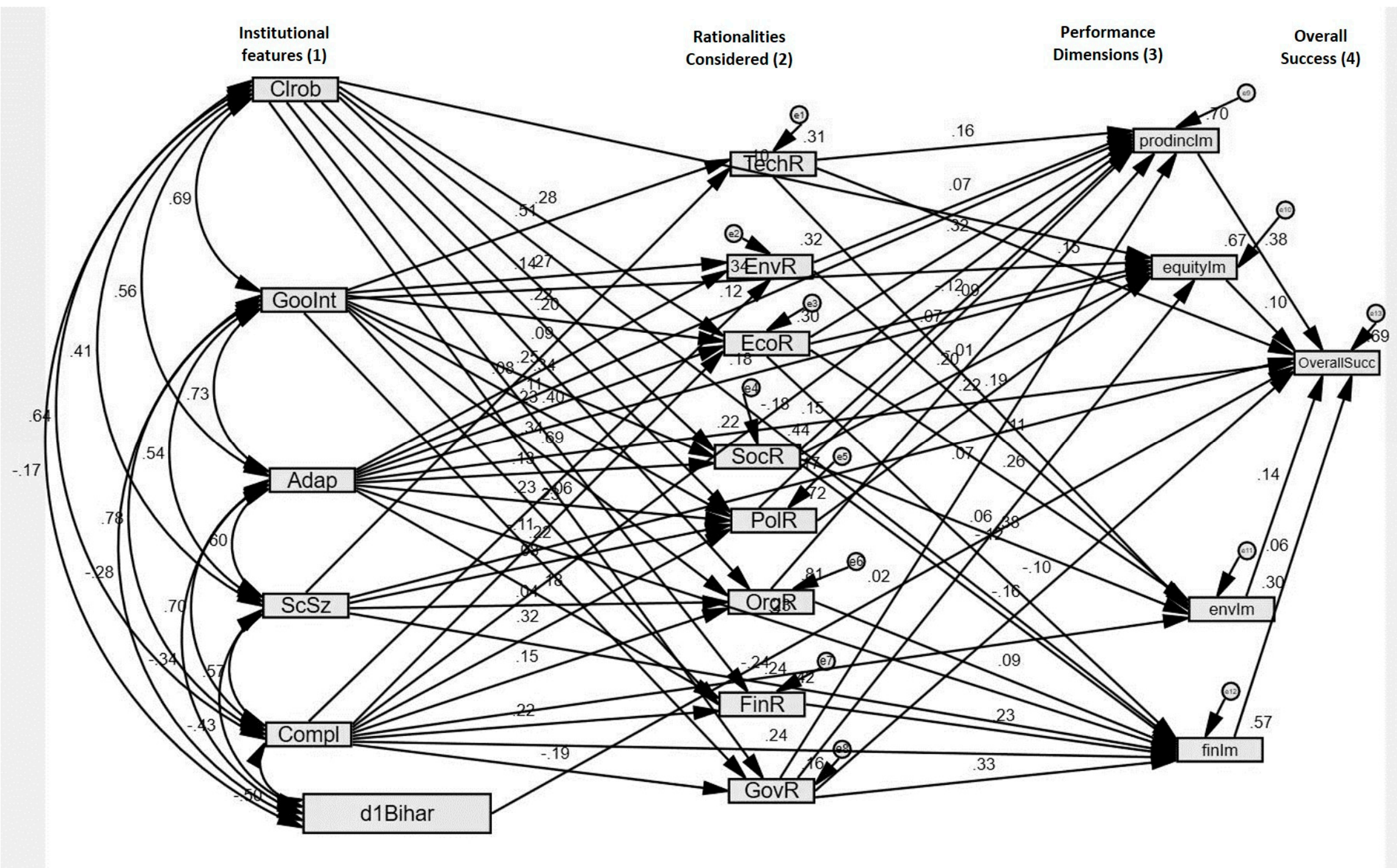

Figure 2. Structural equation modelling (SEM) model. 


\section{Results and Discussion}

\subsection{Structural Equation Model Fit}

The model is recursive, so to check the confirmation of the model, a number of fit statistics were computed and are presented in Table 3. These include root mean square residual (RMR), goodness of fit index (GFI), incremental fit index (IFI), comparative fit index (CFI), root mean square error of approximation (RMSEA), parsimony fit indices (PNFI), and normed Chi-square. The values of model fit indices met most of the acceptance limits, except PNFI (parsimony fit indices) and normed Chi-square.

Table 3. Model fit indices.

\begin{tabular}{ccc}
\hline Fit Indices & Acceptable Value & Study Value \\
\hline Root Mean Square Residual (RMR) & $<0.05$ & 0.039 \\
Goodness of Fit Index (GFI) & $>0.80$ & 0.832 \\
Incremental Fit Index (IFI) & $>0.85$ & 0.884 \\
Comparative Fit Index (CFI) & $>0.85$ & 0.882 \\
Root mean square error of approximation (RMSEA) & $<0.5$ & 0.142 \\
Parsimony Fit Indices (PNFI) & $>0.5$ & 0.455 \\
Normed Chi-square & $(<5$, or possibly <2) & 11.05 \\
\hline
\end{tabular}

Reliability tests were conducted using Cronbach's alpha, which assesses the strength/consistency of measures used in the model. The value was found to be 0.95 , which is acceptable (the range is 0.1 to 1.0 , and anything above 0.7 indicates acceptability) [32]. This indicates that the scales were reliable. Variance inflation factor (VIF) coefficients were used to examine multicollinearity issues in the model, and according to Hair et al. [30], VIF coefficients over 10 indicate problems of multicollinearity. The VIF for each variable was found to be less than 8 , which showed that there was no serious multicollinearity problem.

\subsection{Relationship of Institutional Features to Technical, Environmental, Economic, and Social Rationalities}

The results on the relationship of institutional features to technical, environmental, economic, and social rationalities are given in Table 4. The critical ratio (C.R.) statistics (z statistic) exceed the norm of 1.96 for all except two variables, indicating that the coefficients are statistically significant. The results align with the hypotheses derived from the conceptual framework that institutional features are positively related to achievement of technical, environmental, and economic rationalities. More specifically, the finding indicate that good interaction and appropriate scale have statistically significant and positive relationships with the achievement of technical rationality. Similarly, adaptiveness and compliance have statistically significant and positive relationships with achieving environmental rationality. Clarity of objectives and adaptiveness have positive relationships with achievement of economic rationality. Clarity of objectives, adaptiveness, and good interactions have significantly positive relationships with social rationality.

Table 4. Institutional features and rationalities (Pathways 1-2).

\begin{tabular}{|c|c|c|c|c|c|c|}
\hline Rationalities & & Institutional Features & Estimate & S.E. ${ }^{1}$ & C.R. ${ }^{2}$ & $\mathbf{P}^{3}$ \\
\hline TechR & $<-$ & GoodInt & 0.341 & 0 & 11 & $* * *$ \\
\hline TechR & $<-$ & $\mathrm{ScSz}$ & 0.116 & 0.1 & 1.9 & 0.1 \\
\hline EnvR & $<-$ & GoodInt & 0.083 & 0 & 2.2 & 0 \\
\hline EnvR & $<-$ & Adap & 0.145 & 0 & 4.4 & $* * *$ \\
\hline EnvR & $<-$ & Compl & 0.155 & 0 & 3.8 & $* * *$ \\
\hline EcoR & $<-$ & Clrob & 0.245 & 0 & 5.3 & $* * *$ \\
\hline EcoR & $<-$ & Adap & 0.168 & 0 & 4 & $* * *$ \\
\hline EcoR & $<-$ & Compl & -0.089 & 0.1 & -1.7 & 0.1 \\
\hline SocR & $<-$ & Clrob & 0.203 & 0 & 5.8 & $* * *$ \\
\hline SocR & $<-$ & GoodInt & 0.218 & 0 & 6 & $* * *$ \\
\hline SocR & $<-$ & Adap & 0.078 & 0 & 2.5 & 0 \\
\hline
\end{tabular}

${ }^{1}$ Standard Error, ${ }^{2}$ Critical Ratio, ${ }^{3}$ Probability Value, ${ }^{* * *}$ Significant at the $99 \%$ level. 


\subsection{Relationship of Institutional Features to Political, Organizational, Financial, and Government Rationalities}

The C.R. statistics ( $z$ statistic) exceed the norm of 1.96 for all except two variables, indicating that the coefficients are statistically significant. The results indicate that four out of five institutional features as mentioned in the conceptual framework have a positive and significant relationship with political rationality. Moreover, good interaction is found to have strong relationships with achievement of not only organizational rationality, but also political, financial, and government rationalities. Findings show that compliance plays a statistically significant and positive role in the achievement of political, organizational, and financial rationalities. Appropriate scale is found to significantly influence political and financial rationalities. The results are given in Table 5.

Table 5. Institutional features and rationalities (Pathways 1-2 contd.).

\begin{tabular}{|c|c|c|c|c|c|c|}
\hline Rationalities & & Institutional Features & Estimate & S.E. & C.R. & $\mathbf{P}$ \\
\hline PolR & $<-$ & Clrob & 0.187 & 0 & 6.6 & $* * *$ \\
\hline PolR & $<-$ & GoodInt & 0.288 & 0 & 9.1 & $* * *$ \\
\hline PolR & $<-$ & Adap & -0.045 & 0 & -1.7 & 0.1 \\
\hline PolR & $<-$ & ScSz & 0.115 & 0 & 2.5 & 0 \\
\hline PolR & $<-$ & Compl & 0.259 & 0 & 7.8 & $* * *$ \\
\hline OrgR & $<-$ & Clrob & 0.108 & 0 & 3.3 & $* * *$ \\
\hline OrgR & $<-$ & GoodInt & 0.698 & 0 & 20 & $* * *$ \\
\hline OrgR & $<-$ & $\mathrm{ScSz}$ & 0.082 & 0.1 & 1.6 & 0.1 \\
\hline OrgR & $<-$ & Compl & 0.171 & 0 & 4.5 & $* * *$ \\
\hline FinR & $<-$ & Clrob & 0.1 & 0 & 2.2 & 0 \\
\hline FinR & $<-$ & GoodInt & 0.183 & 0.1 & 3.6 & $* * *$ \\
\hline FinR & $<-$ & Adap & 0.139 & 0 & 3.4 & $* * *$ \\
\hline FinR & $<-$ & Compl & 0.204 & 0.1 & 3.8 & $* * *$ \\
\hline GovR & $<-$ & Clrob & 0.283 & 0 & 5.8 & $* * *$ \\
\hline GovR & $<-$ & GoodInt & 0.157 & 0.1 & 3.1 & 0 \\
\hline GovR & $<-$ & Compl & -0.152 & 0.1 & -2.8 & 0 \\
\hline
\end{tabular}

\subsection{Relationship of Rationalities and Institutional Features to Performance on Different Goals}

Table 6 shows the results on the relationship of shortlisted rationalities and institutional features with various performance on various goals. The C.R. statistics ( $\mathrm{z}$ statistic) exceed the norm of 1.96 for all except one variable, indicating that the coefficients are statistically significant. The results indicate that the performance on production/economic goals is positively and significantly related to technical, economic, and organizational rationality. It is also positively related to environmental and government rationality. Institutional features of adaptiveness and compliance are also positively and significantly related to achievement of production/economic goals. Good outcomes on production/economic goals requires particular attention to these rationalities and institutional features. Another important goal of WUAs is better equity in distribution of the resource and the benefits. The results indicate that the performance on equity goals is positively and significantly related to clarity of objectives, good interaction, and adaptiveness. A statistically significant and positive relationship is also found between technical, environmental, and social rationalities and achievement on environmental goals. Because the poor farmers often farm on more environmentally fragile/poor lands, environmental rationality may lead to significant benefits to them and for equity. Good outcome on financial goals is found to be positively and significantly related to institutional features of clear objectives, adaptiveness, right scale, and compliance. 
Table 6. Rationalities, institutional features, and performance (Pathway 2-3 and 1-3).

\begin{tabular}{|c|c|c|c|c|c|c|}
\hline $\begin{array}{l}\text { Performance } \\
\text { Goals }\end{array}$ & & $\begin{array}{c}\text { Rationalities and } \\
\text { Institutional Features }\end{array}$ & Estimate & S.E. & C.R. & $\mathbf{P}$ \\
\hline prodincIm & $<-$ & TechR & 0.141 & 0.026 & 5.366 & $* * *$ \\
\hline prodincIm & $<-$ & EnvR & 0.071 & 0.031 & 2.285 & 0.022 \\
\hline prodincIm & $<-$ & EcoR & 0.266 & 0.024 & 11.146 & $* * *$ \\
\hline prodincIm & $<-$ & SocR & -0.112 & 0.03 & -3.684 & $* * *$ \\
\hline prodincIm & $<-$ & PolR & 0.055 & 0.037 & 1.505 & 0.132 \\
\hline prodincIm & $<-$ & OrgR & 0.121 & 0.028 & 4.387 & $* * *$ \\
\hline prodincIm & $<-$ & GovR & 0.059 & 0.023 & 2.605 & 0.009 \\
\hline prodincIm & $<-$ & Adap & 0.073 & 0.023 & 3.132 & 0.002 \\
\hline prodincIm & $<-$ & Compl & 0.152 & 0.032 & 4.707 & $* * *$ \\
\hline envIm & $<-$ & TechR & 0.152 & 0.034 & 4.41 & $* * *$ \\
\hline envIm & $<-$ & EnvR & 0.099 & 0.041 & 2.406 & 0.016 \\
\hline envIm & $<-$ & EcoR & 0.194 & 0.031 & 6.25 & $* * *$ \\
\hline envIm & $<-$ & SocR & 0.324 & 0.039 & 8.331 & $* * *$ \\
\hline envIm & $<-$ & Compl & -0.151 & 0.032 & -4.751 & $* * *$ \\
\hline equityIm & $<-$ & Clrob & 0.096 & 0.038 & 2.526 & 0.012 \\
\hline equityIm & $<-$ & GooInt & 0.266 & 0.041 & 6.48 & $* * *$ \\
\hline equityIm & $<-$ & Adap & 0.14 & 0.03 & 4.692 & $* * *$ \\
\hline finIm & $<-$ & Clrob & -0.139 & 0.036 & -3.887 & $* * *$ \\
\hline finIm & $<-$ & Adap & 0.152 & 0.031 & 4.929 & $* * *$ \\
\hline finIm & $<-$ & $\mathrm{ScSz}$ & 0.324 & 0.052 & 6.189 & $* * *$ \\
\hline finIm & $<-$ & Compl & 0.181 & 0.039 & 4.598 & $* * *$ \\
\hline
\end{tabular}

*** Significant at the $99 \%$ level.

\subsection{Relationship of Performance on Different Goals, Rationalities, and Institutional Features to Overall Performance/Success}

Table 7 shows the results on the relationship of shortlisted goal performance, rationalities, and institutional features with overall performance/success. The C.R. statistics (z statistic) exceed the norm of 1.96 for all except one variable, indicating that the coefficients are statistically significant. The results show that that overall success is positively and significantly related to performance on production/economic goals, environmental goals, and equity goals. It is also positively related to performance on financial goals. Among the rationalities and institutional features in direct relation, overall success is positively and significantly related to technical rationality, and to the institutional features of adaptiveness and right scale. The results show that there are a large number of different direct and indirect relationships between overall success, performance on different goals, rationalities, and institutional features, indicating the relevance and usefulness of the conceptual framework.

The results showing all the statistically significant and positive pathways are depicted in Figure 3. Examination of the pathways shows that overall success of the water institutions is closely related to the performance on the goals of production/incomes, equity, and the environment (coefficients $0.448,0.091$, and 0.189 , respectively, all significant at 99\%). The high significance of production/income goals is in line with expectations [22,23] and would be of greatest importance to farmers, but finance is not found to be a significant determinant. Success is also directly related to technical rationality, adaptiveness, and the right scale (coefficients $0.162,0.106$, and 0.259 , respectively, all significant at 99\%) and this is similar to other studies [22,23], including the high importance of right scale, which is a major goal of participatory irrigation management (PIM). The performance on production/income goals is in turn strongly determined by achievement of technical, economic, and organizational rationalities (coefficients 0.141, 0.266, and 0.121, respectively, all significant at 99\%), and this is in line with other studies [22,23], and to institutional features of adaptiveness and compliance. The performance on equity goals is related closely to institutional features of good interaction and adaptiveness (coefficients 0.266 and 0.140 , respectively, both significant at 99\%), and though adaptiveness has been identified as important earlier [22], the identification of good interaction is new and reflects the importance of the participatory approach. The performance on environmental goals requires good achievements on technical, economic, and social rationalities as well as the institutional feature of compliance. The achievement of technical rationality is in turn closely related to the institutional feature of good 
interaction, and economic rationality is related to clear objectives and adaptiveness. The achievement of social rationality is closely linked to clear objectives and good interaction, and organizational rationality to clear objectives, good interaction, and compliance. Thus, the SEM results identify numerous important behavioral pathways leading from the different institutional features and rationalities to performance on different goals as well as perceived overall success of the water institutions. For example, clear objectives lead to good achievement of economic, social, and organizational rationalities. Good interaction leads to better achievement of technical, social, and organizational rationalities, as well as better performance on equity goals. Having appropriate scale/size is directly associated with overall success. Technical rationality leads to better achievement on production and environmental goals, as well as directly determines overall success. Good outcomes on production, equity, and environmental goals determine overall success.

Table 7. Overall success and performance dimensions (Pathway 3-4).

\begin{tabular}{|c|c|c|c|c|c|c|}
\hline $\begin{array}{c}\text { Overall } \\
\text { Performance/Success }\end{array}$ & & $\begin{array}{c}\text { Selected Goal Performance, } \\
\text { Rationalities, and Institutional } \\
\text { Features }\end{array}$ & Estimate & S.E. & C.R. & $\mathbf{P}$ \\
\hline OverallSucc & $<-$ & envIm & 0.189 & 0.036 & 5.305 & $* * *$ \\
\hline OverallSucc & $<-$ & finIm & 0.062 & 0.038 & 1.657 & 0.098 \\
\hline OverallSucc & $<-$ & equityIm & 0.091 & 0.034 & 2.69 & 0.007 \\
\hline OverallSucc & $<-$ & $\mathrm{ScSz}$ & 0.259 & 0.051 & 5.066 & $* * *$ \\
\hline OverallSucc & $<-$ & TechR & 0.162 & 0.032 & 5.071 & $* * *$ \\
\hline OverallSucc & $<-$ & d1Bihar & 0.39 & 0.45 & 0.884 & 0.337 \\
\hline
\end{tabular}

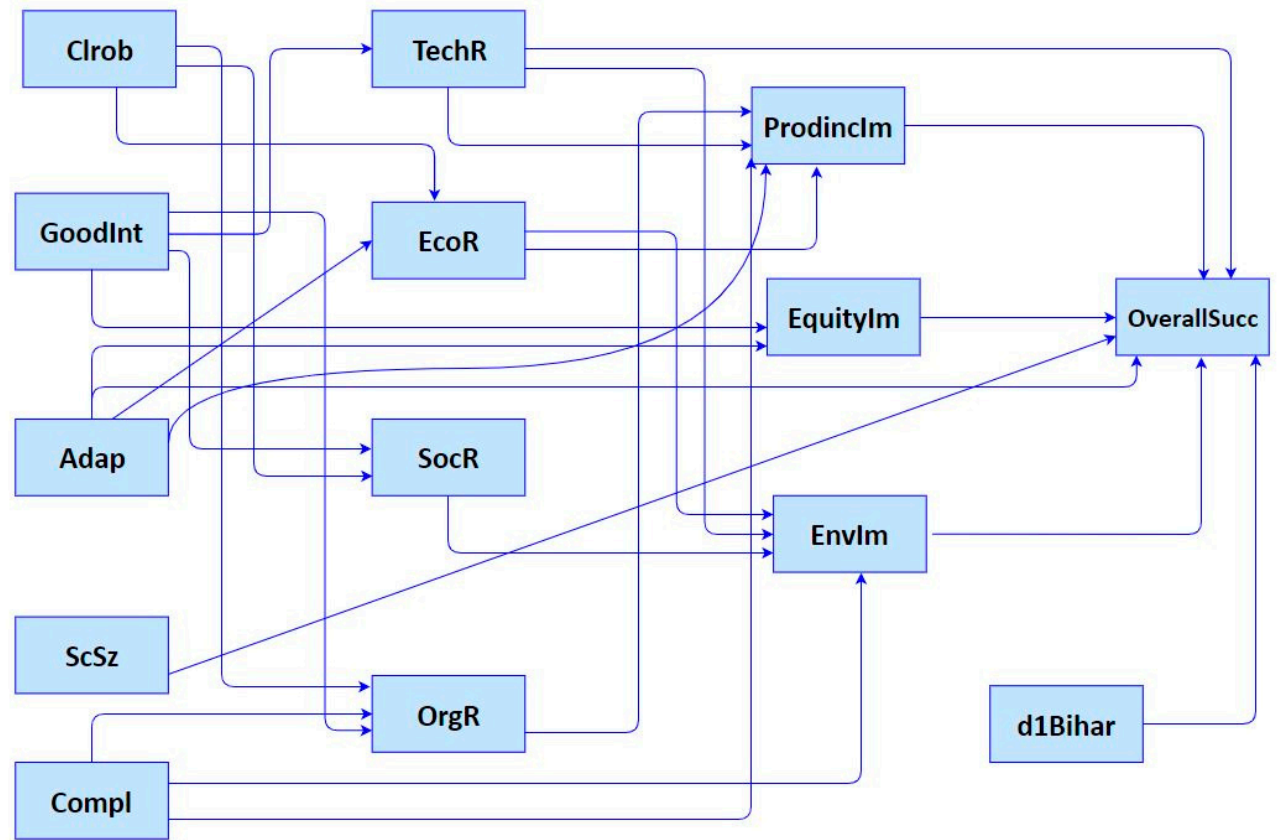

Figure 3. Recursive SEM model.

\section{Conclusions}

Physical development of irrigation has made considerable progress in India, but significant institutional weaknesses exist in the distribution of water, which greatly reduce efficiency and lead to a large gap between potential created and utilized in irrigation. The World Bank [5] finds substantial weakness in the institutional arrangements in eastern India and emphasizes the importance of bringing 
cooperation of the stakeholders for better outcomes. It recommends a resource-led strategy with reformed and strengthened institutions. The research uses structural equation modelling to examine the nature and performance of participatory water institutions in the eastern Indo-Gangetic plains. The basic conceptualization comes from the foundations of new institutional economics and management governance theory, which indicate the importance of addressing a set of rationalities and institutional features to enhance institutional performance. However, it is not clear how they interact with each other and what the pathways are through them to successful outcomes. A structural equation model is used, which allows for interaction and pathways through various institutional characteristic to different performance outcomes.

The results show that overall success of the water institutions (as perceived by the users/members) is closely related to the performance on the goals of production/incomes, equity, and the environment. Success is also directly linked to the achievements of technical rationality, adaptiveness, and the right scale. The performance on production/income goals is in turn strongly related to addressing of technical, economic, and organizational rationalities (coefficients 0.141, 0.266, and 0.121, respectively, all significant at 99\%) and to institutional features of adaptiveness and compliance. The performance on equity goals is determined closely by institutional features of good interaction and adaptiveness. The performance on environmental goals requires achievements of technical, economic, and social rationalities (coefficients 0.152, 0.194, and 0.324, respectively, all significant at 99\%) as well as the institutional feature of compliance. The achievement of technical rationality is in turn closely related to addressing the institutional feature of good interaction, and economic rationality to clear objectives and adaptiveness. Social rationality achievement is closely linked to clear objectives and good interaction, and organizational rationality to clear objectives, good interaction, and compliance (coefficients 0.108 , 0.698 , and 0.171 , respectively, all significant at 99\%). Limitations of the study include the use of Likert-scales for obtaining responses on different aspects, and the assumptions of the econometric techniques used. On a number of technical matters, the data is scarce or not available, and so the measures used are perceived status or changes as seen by farmers. It is assumed that these responses given by the farmers reflect well the underlying reality. Tests including Cronbach's alpha and VIF coefficient indicate that the responses have acceptable properties. Another limitation is the given sample of institutions and beneficiaries covered, which may or may not represent the population. The findings should be interpreted within the perspective of these limitations. Future research may explore the use of actual performance measures such as increase in crop yields or improvement in water use efficiency. It can also explore the impact of specific actions such as improved maintenance, better prices and infrastructure, and greater compliance.

From the implications and policy point of view, the results show the great importance of sound technical rationality for success. This includes experts providing sound technical advice, plans, and training, establishment of quality structures and equipment at the right locations, and regular repair and maintenance. However, technical soundness is not enough; economics advice and help is also needed, such as guidance for right crops and varieties, and good infrastructure and marketing for converting to incomes. In addition, social rationality is also very important and social mobilizers may be needed as a part of the team, also addressing organizational rationality such as member involvement and regular meetings. Apart from these, it will be important to train and guide the farmers so that institutional features are strongly addressed: the objectives are clear to all, regular meetings fostering good interactions are held, the rules/systems are adapted when necessary, the right scale exists through inclusion and devolution, and compliance to the rules is effectively implemented. These can greatly enhance the performance of the water institutions and improve water resource management in the region.

Author Contributions: N.J.--Investigation, methodology, analysis, drafting, and editing; V.P.G. conceptualization, methodology, supervision, drafting and editing; D.J.-Analysis and drafting. All authors have read and agreed to the published version of the manuscript. 
Funding: This research was funded by the Australian Centre for International Agricultural Research (ACIAR) project ADP2014/045.

Acknowledgments: The authors would like to thank numerous researchers for their inputs, ACIAR for their support, state governments for their assistance, respondents for their time, and numerous workshop participants for their helpful comments.

Conflicts of Interest: The authors declare no conflict of interest.

\section{References}

1. Saleth, R.M. Water Institutions in India: Economics, Law and Policy; Commonwealth Publishers: New Delhi, India, 1996; ISBN 978-81-7169-377-1.

2. Gandhi, V.P. Rapporteur's report on institutional framework for agricultural development. Indian J. Agric. Econ. 1998, 53, 552.

3. Crase, L.; Gandhi, V.P. Reforming Institutions in Water Resource Management: Policy and Performance for Sustainable Development; Earthscan: London, UK, 2009; ISBN 978-1-138-86692-8.

4. Gandhi, V.P.; Namboodiri, N.V. Water Resource Management in India: Institutions and Development. In Proceedings of the International Workshop Held in Bangkok, Bangkok, Thailand, 8-9 June 2001; Brennan, D., Ed.; Australian Centre for International Agricultural Research (ACIAR): Canberra, Australia, 2002; pp. 106-130. Available online: https://www.aciar.gov.au/node/8261 (accessed on 20 September 2019).

5. Bank, T.W. India-Development and Growth in Northeast India: The Natural Resources, Water, and Environment Nexus; The World Bank: Washington, DC, USA, 2007; pp. 1-138. Available online: http://documents.worldbank.org/curated/en/940101468034235765/India-Development-and-growthin-Northeast-India-the-natural-resources-water-and-environment-nexus (accessed on 10 October 2019).

6. Gandhi, V.P.; Johnson, N. Enhancing Performance of Participatory Water Institutions in the Eastern Indo-Gangetic Plains: What Can We Learn from New Institutional Economics and Governance Theories? Water 2019, 12, 70. [CrossRef]

7. Ely, R.T. Property and Contract in Their Relations to the Distribution of Wealth; Macmillan: New York, NY, USA, 1922.

8. Commons, J.R. Legal Foundations of Capitalism; Macmillan: New York, NY, USA, 1924.

9. Commons, J.R. Institutional Economics: Its Place in Political Economy; Macmillan: New York, NY, USA, 1934.

10. Marothia, D.; Phillips, W. Analyis of natural resource problems using a synthesis of neoclassical and institutional economics. Asian J. Econ. Soc. Stud. 1985, 4, 263-281.

11. North, D.C. Prologue. In The Frontiers of the New Institutional Economics; Drobak, J.N., Nye, J.V.C., Eds.; Academic Press: San Diego, CA, USA, 1997; pp. 3-12. ISBN 978-0-12-222240-5.

12. Drobak, J.N.; Nye, J.V.C. (Eds.) The Frontiers of the New Institutional Economics; Academic Press: San Diego, CA, USA, 1997; ISBN 978-0-12-222240-5.

13. Williamson, O.E. Economic Institutions and Development: A View from the Bottom. In A Not-So-Dismal Science; Olson, M., Kähköhnen, S., Eds.; Oxford University Press: Oxford, UK, 2007; ISBN 978-0-19-829490-0.

14. Ostrom, E. Crafting Institutions for Self-Governing Irrigation Systems; Institute for Contemporary Studies Press: San Francisco, CA, USA, 1992; ISBN 978-1-55815-168-0.

15. Crase, L.; Dollery, B.; Lockwood, M. Transaction Costs Emanating from Policy Flexibility in Water Markets. In Proceedings of the International Workshop Held in Bangkok, Bangkok, Thailand, 8-9 June 2001; Brennan, D., Ed.; Australian Centre for International Agricultural Research (ACIAR): Canberra, Australia, 2002; pp. 31-47. Available online: https://www.aciar.gov.au/node/8261 (accessed on 12 October 2019).

16. Herath, G. Issues in Irrigation and Water Management in Developing Countries with Special Reference to Institutions. In Proceedings of the International Workshop Held in Bangkok, Bangkok, Thailand, 8-9 June 2001; Brennan, D., Ed.; Australian Centre for International Agricultural Research (ACIAR): Canberra, Australia, 2002; pp. 149-160. Available online: https://www.aciar.gov.au/node/8261 (accessed on 15 October 2019).

17. Pagan, P. Laws, Customs and Rules: Identifying the Characteristics of Successful Water Management Institutions. In Reforming Institutions in Water Resource Management: Policy and Performance for Sustainable Development; Gandhi, V.P., Crase, L., Eds.; Earthscan: London, UK, 2009; pp. 20-44. 
18. Pagan, P.; Crase, L.; Gandhi, V.P. Institutional Constraints and the Necessity to Consider Organisational Dynamics: The Case of Inter-Jurisdictional Water Trade between the Australian Capital Territory and New South Wales. In Reforming Institutions in Water Resource Management: Policy and Performance for Sustainable Development; Crase, L., Gandhi, V.P., Eds.; Earthscan: London, UK, 2009; pp. 20-44.

19. Handbook of Organizational Design: 1: Adapting Organizations to Their Environments; Nystrom, P.C.; Starbuck, W.H. (Eds.) Oxford University Press: Oxford, UK, 1981; ISBN 978-0-19-827241-0.

20. Groth, L. Future Organizational Design: The Scope for the IT-Based Enterprise; Wiley Series in Information Systems; John Wiley \& Sons: Chichester, UK, 1999; ISBN 978-0-471-98893-9.

21. Ackroyd, S. The Organization of Business: Applying Organizational Theory to Contemporary Change; Oxford University Press: Oxford, UK, 2002; ISBN 978-0-19-874269-2.

22. Gandhi, V.P. A Conceptual Framework for Studying Institutions in Watershed Development; Working Paper. No. 2010-11-04; Indian Institute of Management Ahmedabad: Ahmedabad, India, 2010; Available online: https: //web.iima.ac.in/assets/snippets/workingpaperpdf/2010-11-04Gandhi.pdf1 (accessed on 17 October 2019).

23. Gandhi, V.P.; Roy, A.; Crase, L. Water Institutions in the States of Andhra Pradesh, Gujarat and Maharashtra in India: An Empirical Study. In Reforming Institutions in Water Resource Management: Policy and Performance for Sustainable Development; Crase, L., Gandhi, V.P., Eds.; Earthscan: London, UK, 2009; pp. 20-44.

24. Bollen, K.A. Structural Equations with Latent Variables; Wiley Series in Probability and Mathematical Statistics; Wiley: New York, NY, USA, 1989; ISBN 978-0-471-01171-2.

25. Cunningham, E.G. A Practical Guide to Structural Equation Modelling Using Amos; Statsline: Melbourne, Australia, 2008; ISBN 978-0-9805336-0-6.

26. Pearl, J. Causality: Models, Reasoning, and Inference; Cambridge University Press: Cambridge, UK, 2000; ISBN 978-0-521-89560-6.

27. Cooper, B. What drives compliance? An application of the theory of planned behaviour to urban water restrictions using structural equation modelling. Appl. Econ. 2017, 49, 1426-1439. [CrossRef]

28. Ullman, J.B. Structural Equation Modelling. In Using Multivariate Statistics; Tabachnick, B.G., Fidell, L.S., Eds.; Always Learning; Pearson: Boston, MA, USA, 2013; ISBN 978-0-205-89081-1.

29. Schreiber, J.B.; Nora, A.; Stage, F.K.; Barlow, E.A.; King, J. Reporting Structural Equation Modeling and Confirmatory Factor Analysis Results: A Review. J. Educ. Res. 2006, 99, 323-338. [CrossRef]

30. Hair, J.F.; Black, W.C.; Babin, B.J.; Anderson, R.E. Multivariate Data Analysis, 7th ed.; Always Learning; Pearson Education Limited: Harlow, UK, 2014; ISBN 978-1-292-02190-4.

31. Arbuckle, J.L. Amos; IBM SPSS: Armonk, NY, USA, 2019.

32. Cortina, J.M. What is coefficient alpha? An examination of theory and applications. J. Appl. Psychol. 1993, 78, 98-104. [CrossRef]

(C) 2020 by the authors. Licensee MDPI, Basel, Switzerland. This article is an open access article distributed under the terms and conditions of the Creative Commons Attribution (CC BY) license (http://creativecommons.org/licenses/by/4.0/). 